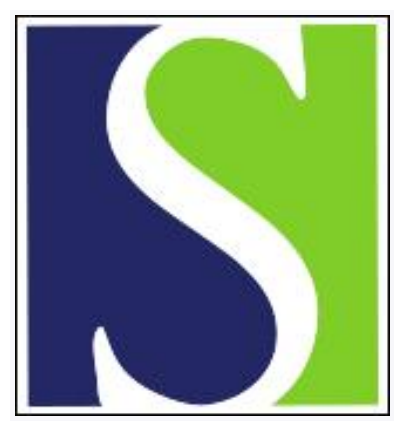

Scand J Work Environ Health 1981;7(4):263-270

https://doi.org/10.5271/sjweh.2548

Issue date: Dec 1981

Hearing damage risk to divers operating noisy tools under water.

by Molvaer OI, Gjestland T

Key terms: diver; diving; hearing damage; hearing damage risk; high pressure; noise; noisy tool; pneumatic rock drill; risk; under water; water; water jet

This article in PubMed: www.ncbi.nlm.nih.gov/pubmed/7347911

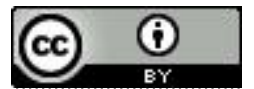




\title{
Hearing damage risk to divers operating noisy tools under water
}

\author{
by Otto Inge Molvaer, MD, ${ }^{1}$ Truls Gjestland, $\mathrm{MSc}^{2}$
}

\begin{abstract}
MOLVAER OI, GJESTLAND T. Hearing damage risk to divers operating noisy tools under water. Scand $j$ work environ health 7 (1981) 263-270. During the measurement of noise generated inside a standard hard hat and the underwater noise level produced by a pneumatic rock drill and two different high-pressure water jet lances commonly used in underwater work, noise levels were recorded of up to $170.5 \mathrm{~dB}(\mathrm{~A})$, in relation to a pressure of $1 \mu \mathrm{Pa}$, in the water close to the divers' heads. Fortunately, the noise is attenuated by the hoods/helmets worn by the divers and the raised hearing threshold in water and compressed gas. The recorded temporary threshold shifts indicate, however, that lengthy exposure might be hazardous to divers' hearing. This possibility is confirmed by a comparison of the noise levels observed in the present study with hearing damage risk criteria.
\end{abstract}

Key terms: diving, high pressure water jet, noise, pneumatic rock drill.

High level noise in air at atmospheric pressure is a well-recognized hazard to hearing. Less attention has been paid to the increasing acoustical stress experienced by underwater workers, in spite of the fact that divers have always been regarded as hard of hearing (5).

Propeller noise in a harbor regularly amounts to levels of $146 \mathrm{~dB}(\mathrm{~A})$ and more, in relation to a pressure of $1 \mu \mathrm{Pa}$, much of the energy being located in the lower frequency range (6). Divers use a multitude of noisy tools under water, and, because of complaints from divers and frequent findings of noise damage in their audiograms, we started a research program in this field. The objective of the investigation was to decide whether the noise from the normal operation of pneumatic rock drills and high pressure water jets under water represents a hazard to the

1 Norwegian Underwater Institute, Bergen, Norway.

2 Electronics Research Laboratory, The Norwegian Institute of Technology, University of Trondheim, Trondheim, Norway.

Reprint requests to: Dr OI Molvaer, Norwegian Underwater Institute, N-5034 Ytre Laksevaag, Norway. hearing of divers wearing different, commonly-used diving gear. Since some commercial divers have complained about dizziness after the operation of highpressure water jets, we also observed vestibular function.

Parker et al (18) found that infrasound produced nystagmus in guinea pigs and interpreted this observation as supporting the hypothesis that acoustical stimuli may activate the receptors of the vestibular apparatus. Miller (14) reported disturbances of equilibrium, vertigo, and nystagmus at levels of about $130-150 \mathrm{~dB}$, and Bergot (4) suggested $140 \mathrm{~dB}$. Anticaglia (2) reported similar phenomena for $120 \mathrm{~dB}$ and upwards. Montague \& Strickland's subjects (16) experienced rotational movements of the visual field, interpreted as caused by acoustical stimulation of the vestibular apparatus, at or above sound pressures of approximately $165 \mathrm{~dB}$, in relation to a pressure of $20 \mu \mathrm{Pa}$ when diving without a hood. Wearing neoprene hoods, they did not experience any such phenomena, even at $180 \mathrm{~dB}$, which was the maximum output of the system. In addition the vestibular effects disappeared immediately when the test signal was switched off. 


\section{Materials and methods}

The noise exposure test took place at a depth of $7.5 \mathrm{~m}$ in the sea in a wide, open bay on rocky bottom, while the damping capability studies were performed in an indoor 5 - by $7-\mathrm{m}$ wide and $3.5-\mathrm{m}$ deep concrete pool.

All three subjects had 13 a of diving experience. Two of them had perfectly normal hearing, but the third had a perceptive dip to $25 \mathrm{~dB}$ (in relation to ISO 389) (11) at $6 \mathrm{kHz}$ in one ear. This last diver wore a standard Siebe-Gorman hard hat and a standard suit. In this equipment the breathing air is pumped continuously from the surface to the diver, who regulates the flow out of the helmet by operating a valve next to his right ear. This continuous air flow represents a not insignificant noise source, especially as it bubbles out into the water. The communicaton system is another source. This metal helmet is roomy enough for the diver to turn his head freely inside, and thus his ears will change position in relation to the different sound sources, although the position maintained most of the time is looking straight ahead through the faceplate.

One diver wore a Superlite 17 helmet (Diving Systems International) made of fiber glass and a hot water suit. This helmet is lined with $18 \mathrm{~mm}$ of foam rubber in which there are pockets next to the ears for the earphones, which are covered by $2 \mathrm{~mm}$ of foam rubber. The helmet seals around the neck leaving the ears and head dry. The nose and mouth are sealed off from the rest of the helmet by an oronasal mask in front of which is mounted a demand valve. This valve normally delivers breathing gas only when the diver inhales (although in an emergency it may be set in a free flow position).

The third diver wore a Comex pro band mask which seals around the face leaving the ears and head wet, covered only by a $5 \mathrm{~mm}$-thick neoprene rubber hood. This material contains gas sealed off in numerous minute spheres and is therefore compressible. A band mask also has an oronasal inner mask and a demand valve as already described. This diver wore a hot water suit as well.
An unmodified hand-held Atlas Copco pneumatic drill, type $\mathrm{RH} 5713 \mathrm{~L}$, taking $3 \mathrm{~m}^{3}$ of air per minute from a compressor at the surface, was used for the rock drilling.

A high-pressure water jet is a tool commonly used to clear underwater structures for marine growth and rust and to remove concrete from pipelines. Water is supplied from a surface-based compressor, and the pressure can be more than 980 bars $(98,000 \mathrm{kPa})$. Most high pressure jet systems use water only, but some add sand as an abrasive. We used a Woma highpressure system with two different, interchangeable guns (lances). In the present test the work pressure varied between 275 and 412 bars $(27,500$ and $41,200 \mathrm{kPa}$, respecitively), water only.

The divers carried a Brüel \& Kjær 8100 connected to a Revox tape recorder tophydrophone fixed to the head gear and side.

After a baseline audiovestibular test (soundproof booth, Danplex AS 62 audiometer, caloric test a.m. Hallpike), one diver at a time performed a dive of 1-h duration at the worksite in the sea without doing any work and had his hearing tested as soon as possible afterwards.

After some hours of rest the SiebeGorman diver operated the rock drill for $1 \mathrm{~h}$. The Superlite 17 diver had to stop after $25 \mathrm{~min}$ due to water entering the oronasal mask through a valve stuck in the open position. The band mask diver unfortunately had to surface after a few minutes due to darkness and entanglement.

All three had their hearing tested as soon as possible after the dive, and the Siebe-Gorman diver had his vestibular function rechecked.

The next day, after a pre-dive audiogram, each diver operated the high-pressure jet for $1 \mathrm{~h}$ and had his hearing checked immediately afterwards. The Superlite and the band mask divers had their vestibular function tested as well.

A Sony ECIM-50 PS microphone was taped to the head of the diver next to his right external auditory canal inside a Siebe-Gorman hat, and the noise from the breathing air was recorded on a Tandberg TC 20 A tape recorder. (Since this miniature microphone is very sensitive to humi- 
dity, this measurement was done only on shore.)

The damping capabilities of the helmets were measured with the same microphone, taped in the position of the external auditory canal on a mannikin head, which was placed in the helmet and put under water in the pool. Octave band filtered noise was produced by an underwater sound source and measured by the same hydrophone, placed in the same position, as in the sea dives. The signals picked up by the microphone were recorded and frequency-analyzed in an octave band analyzer.

\section{Results}

The Siebe-Gorman diver, who had not performed rock drilling for years, found the noise terrible and felt an uncomfortable tickling in his throat. Consequently he was not able to operate the drill for more than a few minutes at a time without a short break. He did not feel dizzy, however. If he squatted and thus changed his position in relation to the air outlet on the drill, the situation became more tolerable. The noise did not interfere with the communication system. He experienced reduced hearing for a couple of hours after the dive.

During rock drilling the Superlite diver felt very little discomfort, no vertigo, and no interference with the communication. (During previous work with that tool he had only worn a neoprene hood and half-mask in which he felt the noise was very uncomfortable.) He operated the drill while kneeling and did not recognize reduced hearing after the dive.

The Siebe-Gorman diver, operating the long, unmodified jet lance, found the noise produced by this tool to be less disturbing than that of the pneumatic rock drill, and he experienced less reduction in hearing afterwards.

The Superlite diver found the noise of the short, modified jet lance comparable to that of the drill, but not disturbing, and he experienced no aftereffects.

The band mask diver did not find the noise from the long jet lance uncomfortable when he aimed the beam at the rock with a working distance of about $5 \mathrm{~cm}$. He found, however, that the loudness doubled when he directed the beam out into open water. But even then he did not find it troublesome, it did not interfere with the communication system, and he did not feel that his hearing was reduced afterwards.

The background noise in the sea was defined as the noise picked up by the hydrophone during the no-work dive. A significant part of this noise was produced by the exhaust air, which was approximately the same in the Superlite helmet. and the band mask, while the Siebe-Gorman hard hat produced a significantly higher noise level (fig 1).

The noise from the three different tools, as picked up by the hydrophone, is illustrated in fig 2 . The corresponding decibel(A) values (in relation to a pressure of $1 \mu \mathrm{Pa}$ ) are 170.5 for the short jet lance, 161 for the long lance, and 141 for the rock drill.

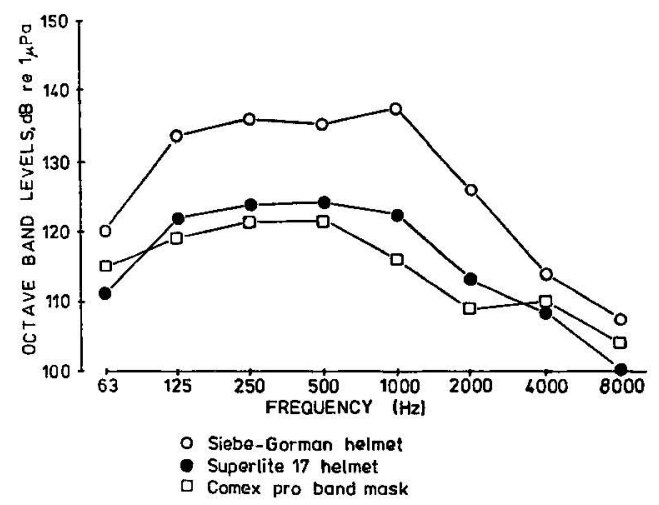

Fig 1. Noise in the water during no-work dives with different diving gear. (Hydrophone in reference position: Close to the diver's ears)

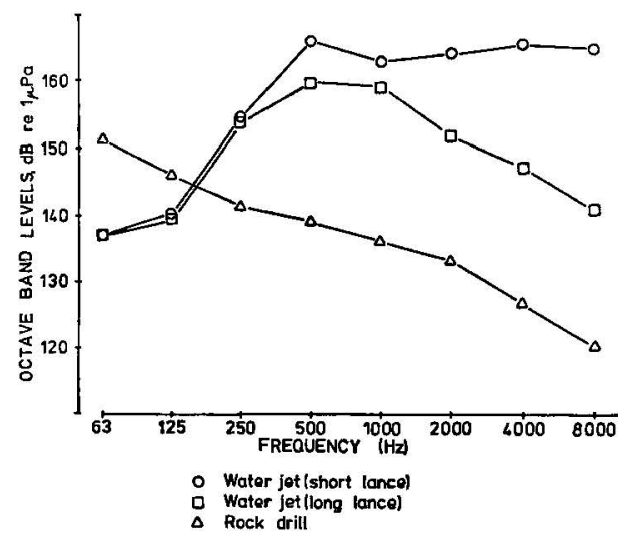

Fig 2. Sound levels in the water during the operation of noisy tools. (Hydrophone in reference position) 
The sound pressure levels (SPLs) inside the Siebe-Gorman hat with the exhaust valve in closed and open positions are shown in fig 3 . The corresponding decibel(A) values are 95.5 , in relation to a pressure of $20 \mu \mathrm{Pa}$, when the valve is closed and 99.5 when open.

The relative damping from the water outside to the air inside the two helmets is shown in fig 4. The damping capabilities of neoprene hoods have been reported by several authors $(10,20)$ and found to be on the order of $20-40 \mathrm{~dB}(30-37 \mathrm{~dB}$ at 1 to $2 \mathrm{kHz}$ ). Montague \& Strickland (16) found no difference between hoods $3 \mathrm{~mm}$, $5 \mathrm{~mm}$, or $6 \mathrm{~mm}$ thick at a depth of $7.5 \mathrm{~m}$. At $1 \mathrm{kHz}$ and above, the damping capability was at least $20 \mathrm{~dB}$.

After $1 \mathrm{~h}$ of diving without operating any tool, the Siebe-Gorman diver acquired a temporary threshold shift (TTS) of a maximum of $15 \mathrm{~dB}$ in the higher frequencies (fig 5). The tympanic membranes were normal, and the hearing test was started 2 min $10 \mathrm{~s}$ after his helmet was taken off. The right ear was measured first in all the audiometric tests.

After $1 \mathrm{~h}$ of rock drilling the TTS was a maximum of $35 \mathrm{~dB}$ (fig 5 ). The tympanic membranes were normal, and the audiometric test was started $5 \mathrm{~min}$ after the diver stopped drilling and $3 \mathrm{~min}$ after the helmet was removed.

After $1 \mathrm{~h}$ of operation of the water jet the TTS was a maximum of $15 \mathrm{~dB}$ with no effect on the lower frequencies (fig 5). The audiometric test was started $4.5 \mathrm{~min}$ after the diver stopped jetting, $3.5 \mathrm{~min}$ after his helmet was taken off. This time, otoscopy revealed insignificant congestion of the tympanic membranes.

Little or no effect on hearing was found

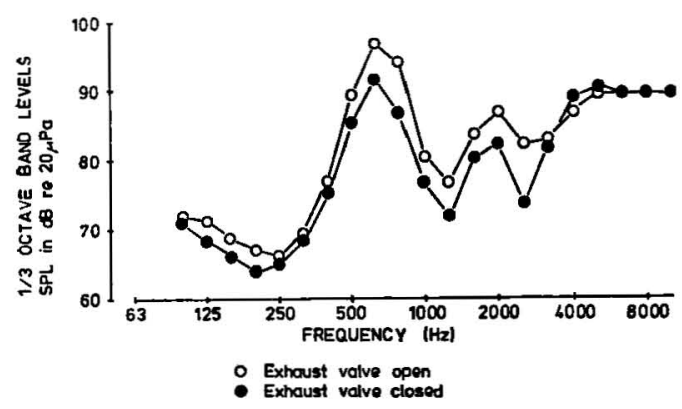

Fig 3. Noise inside the Siebe-Gorman hard hat. (Microphone close to diver's right ear) (SPL = sound pressure level)

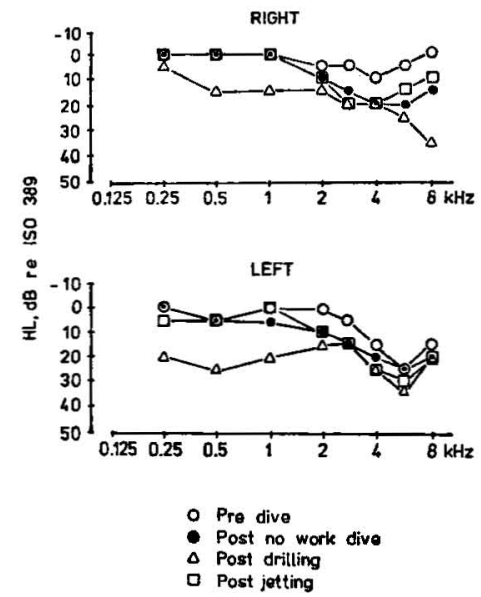

Fig 5. Hearing level (HL) and temporary threshold shifts (TTS) in the Siebe-Gorman diver.

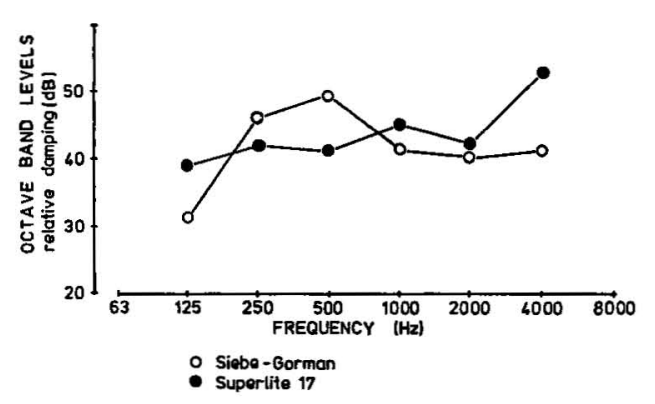

Fig 4. The damping capabilities of the two helmets.

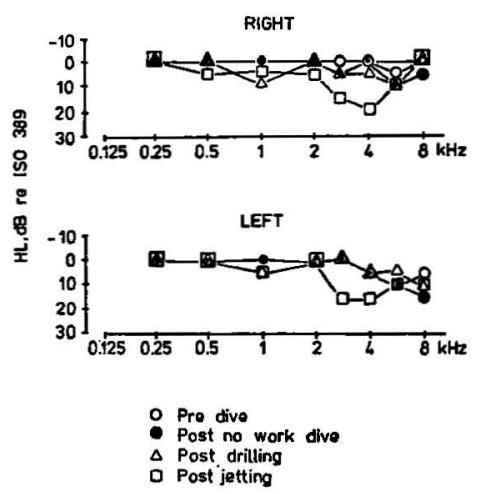

Fig 6. Hearing level (HL) and temporary threshold shifts (TTS) in the Superlite 17 diver. 
in the 1-h, no-work dive of the Superlite diver (fig 6). Measurements commenced $3 \mathrm{~min}$ after the diver surfaced, and his tympanic membranes were found to be normal. Twenty-five minutes of rock drilling did not change the hearing, measured $5 \mathrm{~min}$ after the exposure, significantly either (fig 6). After $1 \mathrm{~h}$ of water jetting the maximum TTS was $20 \mathrm{~dB}$, measured $4.5 \mathrm{~min}$ after the diver stopped jetting (6).

A maximum 10-dB TTS was found in the band mask diver $2.5 \mathrm{~min}$ after $1 \mathrm{~h}$ of "silent" diving (fig 7). Insignificant congestion was demonstrated in his right tympanic membrane.

No significant difference in hearing was found after a 1-h exposure to high-pressure water jetting in comparison to $1 \mathrm{~h}$ of "silent" diving (fig 7). Audiometry started $4.5 \mathrm{~min}$ after the diver stopped jetting, and slight congestion was found in the right Shrapnell's membrane and along the manubrium mallei.

None of the divers felt dizzy during or after the operation of any of the tools, and none of them had nystagmus, spontaneous or positional, in any gaze direction, when coming ashore. Caloric tests (a.m. Hallpike) were normal for all the divers both before and after the noise exposure. The postexposure test of the Siebe-Gorman diver was performed $25 \mathrm{~min}$ after the rock drilling. For the band mask diver it was done $20 \mathrm{~min}$ after the jetting exposure, while for the Superlite diver there was a delay of $2 \mathrm{~h} 40 \mathrm{~min}$ after the jetting.

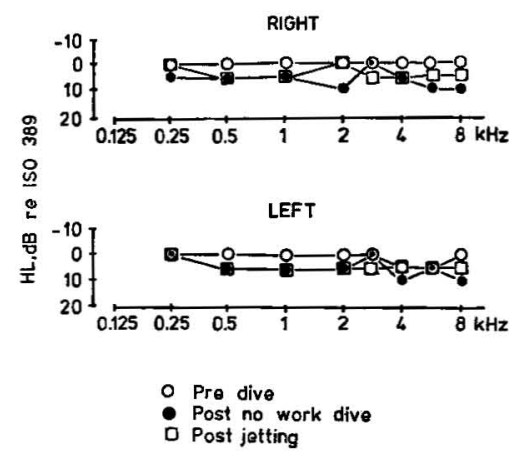

Fig 7. Hearing level $(\mathrm{HL})$ and temporary threshold shifts (TTS) in the band mask diver.

\section{Discussion}

The maximum SPL measured in the water outside the divers' headgear in our investigation was $170.5 \mathrm{~dB}(\mathrm{~A})$, in relation to a pressure of $1 \mu \mathrm{Pa}$, corresponding to $144.5 \mathrm{~dB}(\mathrm{~A})$, in relation to a pressure of $20 \mu \mathrm{Pa}$ (fig 2). This was the noise from the short lance operated only by the Superlite diver, whose headgear attenuated the noise as shown in fig 4 . The noise levels inside that helmet, as shown in fig 8 , were far below any level expected to produce vestibular phenomena. The noise levels inside the Siebe-Gorman helmet (fig 3) did not lead us to expect any vestibular stimulation either.

To evaluate the noise levels experienced by the band mask diver, one must realize that the hearing threshold under water is elevated by 30 to $60 \mathrm{~dB}$ in comparison to the threshold in air (10). This difference is partly due to the loss of the resonator function of the external auditory canal and partly to the impedance mismatch between water and gas. When the ratio of impedance is large at a boundary and the impedance is smallest behind the boundary, the sound pressure at the boundary will be close to 0 . As a consequence of the extreme impedance mismatch between the water in the external auditory canal and the gas in the middle ear, the tympanic membrane will act as a pressure release boundary where positive pressures are reflected as negative and vice versa.

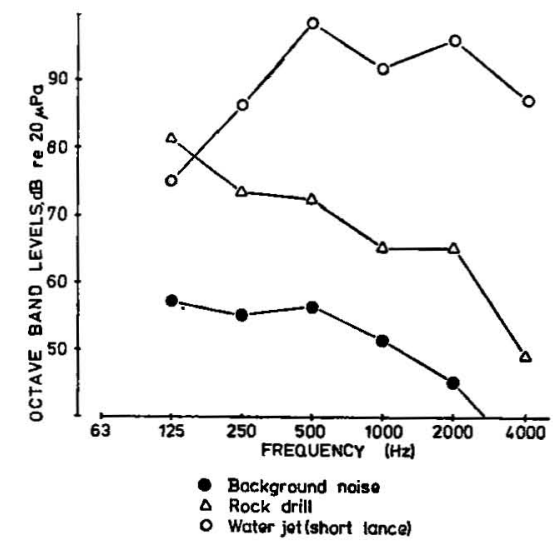

Fig 8. Noise inside the Superlite 17 helmet during a no-work dive, rock drilling, and water jetting. (Calculated from fig 1,2 and 4. Reference changed from 1 to $20 \mu \mathrm{Pa}$.) 
There is much evidence in favor of the view that underwater hearing occurs mainly through bone conduction. Consequently, the attenuating effect of a hood is not reduced by holes corresponding to the external auditory canals. A $2 \times 2$-inch $(5 \times 5-\mathrm{cm})$ hole over the forehead improves, however, the hearing to a level comparable to that of a diver without a hood.

In a previous investigation (15) we found the hearing threshold elevated from approximately $25 \mathrm{~dB}$ at $0.5 \mathrm{kHz}$ to approximately $55 \mathrm{~dB}$ at $8 \mathrm{kHz}$ in a diver wearing a $5-\mathrm{mm}$ neoprene hood at a depth of $3.5 \mathrm{~m}$ in comparison to his hearing in air without a hood. This attenuation represents the combined effect of the elevated hearing threshold under water and the damping effect of the hood. When the described mechanisms are considered, the band mask diver's exposure did not exceed $85 \mathrm{~dB}$, in relation to a pressure of $20 \mu \mathrm{Pa}$, for any one frequency measured from 1 to $8 \mathrm{kHz}$ during the operation of the jet lance; this value is far below the levels reported to produce vestibular phenomena. Moreover, the vestibular effects reported in the literature disappeared when the noise signal was switched off, while our caloric tests were not started until 20,25 and 160 min after the diving.

The SPL recorded from the short jet lance with the retrobaffler was approximately $10 \mathrm{~dB}(\mathrm{~A})$ higher than that from the long, unmodified lance. The shorter distance from the nozzles to the hydrophone $(100 / 115 \mathrm{~cm}$ from the jetting nozzle, $68 / 85 \mathrm{~cm}$ from the retro nozzle) may account for some of the difference since the sound pressure is inversely proportional to the distance from a point source. But since doubling the distance should only halve (ie, reduce by $6 \mathrm{~dB}$ ) the pressure, this alone cannot explain the whole difference in our measurements because the modified lance was not that much shorter. We can however, offer no further explanation at this time.

HM Peart's unpublished data (England) show a linear relationship between water beam pressure and SPL that accounts for a difference of approximately $4 \mathrm{~dB}$ between 275 and 412 bars $(27,500$ and 41,200 $\mathrm{kPa}$, respectively). Peart's highest decibel(A) value was 167 in relation to a pressure of $20 \mu \mathrm{Pa}$, although he had placed the hydrophone closer to the nozzles of the lances than was the case in our experiments. M Collar's unpublished data from Comex, England, did not reveal any change in SPL with changing water beam pressure. He measured up to $172.5 \mathrm{~dB}(\mathrm{~A})$, in relation to a pressure of $20 \mu \mathrm{Pa}$, but the exact distance between the hydrophone and lance was not specified. In our experiments changes in the pressure of the water beam from 275 to 412 bars $(27,500$ to $41,200 \mathrm{kPa}$ ) changed the SPL by approximately $2 \mathrm{~dB}$.

Adolfson \& Fluur (1), Fluur \& Adolfson (9), and Fluur (8) demonstrated that the middle ear mechanism deteriorates in compressed air, and a depth-related reversible conductive hearing loss results which is also frequency dependent. At a pressure corresponding to a depth of $100 \mathrm{~m}$ the mean loss in the middle frequencies was approximately $20 \mathrm{~dB}$ in comparison to surface threshold. Analogous observations are made by several authors for deep heliox diving $(3,7,17,21)$. We do not know what the threshold elevation might be in air at a 7.5-m depth and consequently cannot judge whether this mechanism offered any significant protection in our investigation. In a previous investigation (15) we found the hearing threshold elevated $45-66 \mathrm{~dB}$ in a Superlite diver at a 3.5-m depth in a pool (in comparison to surface threshold without any headgear). If the difference between that threshold and the directly measured attenuation of the Superlite helmet represents the effect of the compressed air on the middle ear mechanism, then it attenuates on the order of 5-15 dB at different frequencies at that depth. Hollien \& Feinstein (10) did not find any difference in free field underwater hearing thresholds between 3.66and $32-\mathrm{m}$ ear depths. But that was under wet conditions, while the ears are dry in a Superlite helmet.

There was no significant TTS in the Superlite diver after the no-work dive, which is well in accordance with the low background noise level. While operating the short jet lance, however, he was exposed to a sound level of $99.5 \mathrm{~dB}(\mathrm{~A})$ in relation to a pressure of $20 \mu \mathrm{Pa}$, a level which according to regulations of the International Organization for Standardiza- 
tion (ISO) (12) should be restricted to less than $1 \mathrm{~h} / \mathrm{d}$. The TTS after the $1-\mathrm{h}$ exposure was correspondingly up to $20 \mathrm{~dB}$ (fig 6).

The sound level inside the Superlite helmet during the operation of the rock drill was $73 \mathrm{~dB}(\mathrm{~A})$ in relation to a pressure of 20 $\mu \mathrm{Pa}$. As could be expected, this noise level had little effect on the hearing after a 30 -min exposure. Fig 6 demonstrates that the difference in hearing between this 30 -min exposure and the 1-h "silent" dive was insignificant. Nevertheless, the noise inside the helmet during rock drilling was above the maximum level not to be exceeded in work in which constant attention and vigilance is needed according to the Norwegian Labor Inspectorate's draft proposal for new regulations (22).

To estimate the exposure of the inner ear in the band mask diver, we have subtracted the attenuation found under water in a previous investigation (15) from the noise level produced by the long jet lance after the curve in fig 2 has been adjusted to a reference pressure of $20 \mu \mathrm{Pa}$ instead of $1 \mu \mathrm{Pa}$. Since our previous attenuation curve stops at $0.5 \mathrm{kHz}$, we have subtracted $20 \mathrm{~dB}$ from the adjusted levels in the lower frequencies. This is the difference between the thresholds in air and under water at 125 and $250 \mathrm{~Hz}(10,16)$. A neoprene hood does not seem to give any protection at these frequencies. Transformed to decibel (A) values, the corrected octave band levels adds up to $104.4 \mathrm{~dB}(\mathrm{~A})$ in relation to a pressure of $20 \mu \mathrm{Pa}$. According to ISO regulation 1999 (12) continuous exposure at that level is permitted for less than 30 $\mathrm{min} / \mathrm{d}$. The application of ISO 1999, however, may be questioned. The risk criteria given in this standard are rather moderate, and the definition of hearing impairment used in it is not approved by Norway. The hearing loss criteria adopted by the Norwegian Health Authorities (19) are far more strict and would reduce permissible exposure significantly in comparison to ISO 1999. Kryter (13) has suggested a revision of ISO 1999 that would lead to the same conclusion.

Nevertheless, the TTS experienced by the band mask diver after a 1-h exposure to $104 \mathrm{~dB}(\mathrm{~A})$ was a mere $5 \mathrm{~dB}$. If our estimation of the noise exposure is correct, the only explanation for the minimal TTS

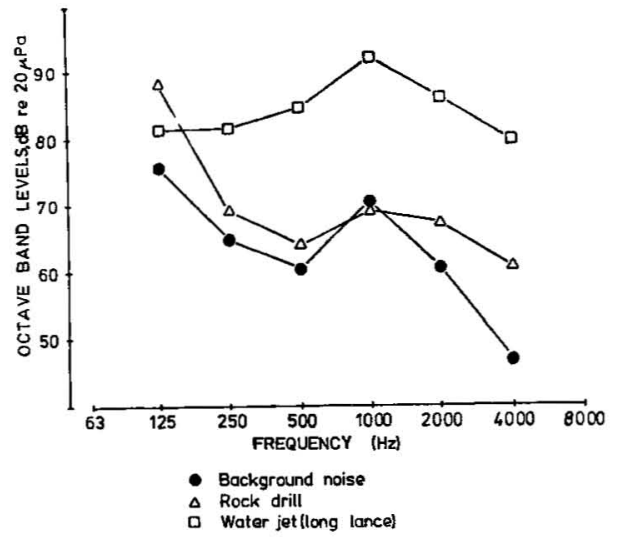

Fig 9. Outside noise assumed to reach the diver's ears in a Siebe-Gorman hard hat during a no-work dive, rock drilling, and water jetting. (Calculated from fig 2, 1 and 4 . The noise generated inside the helmet, fig 3 , is not taken into consideration in these curves.)

we can offer is that this person has a high tolerance to noise. This tolerance is consistent with the fact that his hearing has remained completely normal during 13 a of professional diving during which he used noisy tools.

The noise level of $99.5 \mathrm{~dB}(\mathrm{~A})$ (in relation to a pressure of $20 \mu \mathrm{Pa}$ ) in the Siebe-Gorman helmet was recorded on shore. It is merely conjecture to assume that it is identical during diving, but one would at least not expect a reduction of the level when the helmet is surrounded by a denser medium. According to ISO requirements the maximum permitted exposure to such noise levels is less than $1 \mathrm{~h} / \mathrm{d}$. Nevertheless, this category of divers has been exposed $8 \mathrm{~h} / \mathrm{d}$ for decades, and many of them are hard of hearing.

If we subtract the measured damping effect of the Siebe-Gorman helmet from the noise levels produced by the tools this diver operated, we find, surprisingly, that the noise reaching the ear from outside was insignificant compared to the noise generated inside the helmet itself (fig 9). In accordance with this observation the TTS after the jetting dive was not significantly different from that after the nowork dive.

The TTS after the rock drilling, however, was much greater, especially in the low frequencies. Our explanation is speculative, but from fig 2 it is evident that the drill noise has most of its energy in 
the low frequencies, where the damping capability of the helmet seems to decrease rather abruptly (fig 4 ), whereas the helmet affords the best attenuation in the frequencies where the jet noise is highest (fig $2 \& 4)$.

\section{References}

1. Adolfson J, Fluur E. Hörselförändringar i hyperbar miljö. Försvarsmedicin 1 (1965) $167-171$.

2. Anticaglia JR. Extra-auditory effects of sound on the special senses. In: Welch BL, Welch AS, ed. Physiological effects of noise. Plenum Press, New York, NY 1970, pp $143-150$.

3. Appaix A, Demard F. Etude audiométrique et électro-nystagmographique chez l'homme normal - en plongée très profonde. Acta otolaryngol (Stockh) 73 (1972) $141-147$.

4. Bergot M. Conséquences $d u$ bruit sur l'organisme. Réflexion sur l'état actuel de la question. Méd aéronaut spat méd subaqu hyperbare 16 (1977) 315-324.

5. Bornmann RC. Treatment of inner ear disturbances in diving. In: Lambertsen $\mathrm{CF}$, ed. Proceedings of the symposium on decompression sickness and its therapy in New Orleans 1978. Air Products and Chemicals, Allentown, PA 1979, pp 29-37.

6. Brüel \& Kjær. Introduction to underwater acoustics: Hydrophones - their characteristics and applications: Calibration technique. Nærum, 1980

7. Farmer JC, Thomas WG, Preslar M. Human auditory responses during hyperbaric helium-oxygen exposures. Surg forum 22 (1971) $456-458$

8. Fluur E. L'audition en atmosphére comprimée. Rev physiol subaqu méd hyperbare 2 (1970) 31-33.

9. Fluur E, Adolfson J. Hearing in hyperbaric air. Aerosp med 57 (1966) 783-785.

10. Hollien $\mathrm{H}$, Feinsten $\mathrm{S}$. Hearing in divers. In: Drew EA, Lythogoe JN, Woods JD, ed.
Underwater research. Academic Press, New York, NY 1976, pp 81-138.

11. International Organization for Standardization. Acoustics - Standard reference zero for the calibration of pure-tone audiometers. Geneva 1975. (ISO 389-1975 (E)).

12. International Organization for Standardization. Acoustics - Assessment of occupational noise exposure for hearing conservation purposes. Geneva 1975. (ISO 1999$1975(\mathrm{E})$ ).

13. Kryter KD. Impairment to hearing from exposure to noise. $J$ acoust soc am 53 (1973): 5, 1211-1234.

14. Miller JD. Effects of noise on people. J acoust soc am 56 (1974) 729-764

15. Molvær OI, Gjestland $\mathrm{T}$, Oftedal $\mathrm{T}$, Hatlestad S. Hearing damage risk due to noise from jet tool operated under water. Norwegian Underwater Institute, Bergen 1979, (Rpt no 24, 1979).

16. Montague WE, Strickland JE. Sensitivity of the water-immersed ear to high- and low-level tones. J acoust soc am 33 (1961) $1376-1381$

17. Olivier J-C, Demard F. Effects sur l'audition d'un sejour en atmosphère comprimée d'helium. Rev physiol subaqu méd hyperbare $2(1970) 30$.

18. Parker DE, von Gierke HE, Reschke MA Studies of acoustical stimulation of the vestibular system. Aerosp med 39 (1968) 1321-1325.

19. Quist-Hansen S, Flottorp G. Hørseltap (screening), Larmskade grad I-II-III: Notat. Det audiologiske institutt, Universitet i Oslo, Oslo 1977.

20. Smith PF, Hunter WL Jr. On the effects of exposure to intense underwater sound on navy divers. In: US Navy Submarine Medical Research Laboratory. A report of a conference on the bio-effects of sound. Groton 1980. (Mem Rpt 80-1).

21. Thomas WG, Summitt J, Farmer JC. Human auditory threshold during deep, saturation helium-oxygen dives. $J$ acoust soc am 55 (1974) $810-813$.

22. - De nye støyforskriftene: Store kostnader, men ogsà besparelser. Vern og Velferd, Oslo (1980): 4, 35.

Received for publication: 16 March 1981 